\title{
Violencia política e impunidad en Atoyac de Álvarez, Guerrero. El difícil procesamiento social de un pasado contrainsurgente $(2000-2014)^{*}$
}

\author{
Political Violence and Impunity in Atoyac \\ de Álvarez, Guerrero. The Difficult Social \\ Processing of a Counterinsurgent Past (2000-2014)
}

\author{
Libertad Argüello Cabrera \\ (D) 0000-0002-3490-7079 \\ El Colegio de México, México \\ larguello@colmex.mx
}

Resumen: El caso de Atoyac de Álvarez, un municipio serrano de la Costa Grande de Guerrero, azotado por la guerrilla y la contrainsurgencia en la segunda mitad del siglo xx, permite analizar cómo las dinámicas de violencia e impunidad continuas moldean los alcances institucionales y sociales para tramitar pasados violentos. Desde un diálogo interdisciplinario entre historia y sociología se revisa el entretejido de diversas condiciones macro y meso sociopolíticas que dificultan el procesamiento de este pasado a nivel local, en un periodo que abarca desde la alternancia del partido en el poder ejecutivo federal (2000) hasta la entrega del informe final de la Comisión de la Verdad para Guerrero (2014). La investigación evidencia que las luchas por la verdad y la justicia están atravesadas por una situación de violencia crónica, alimentada por profundos antagonismos sociopolíticos, precarias condiciones de seguridad personal y actuaciones institucionales lentas y selectivas.

Palabras clave: violencia crónica; impunidad; contrainsurgencia; verdad y justicia; Guerrero.

* Este trabajo se deriva de una investigación doctoral inédita, desarrollada entre 2012 y 2016 en el marco del Programa de Doctorado en Ciencia Social con Especialidad en Sociología, Centro de Estudios Sociológicos, El Colegio de México.

Secuencia, ISSN 0186-0348, núm. 102 | septiembre-diciembre de 2018 | pp. 257-284 257 
Abstract: The case of Atoyac de Álvarez, a mountain municipality on the Costa Grande of Guerrero, ravaged by guerrillas and counterinsurgents during the second half of the 20th century, allows us to analyze how the dynamics of violence and impunity continue to shape the institutional and social sphere to process violent pasts. On the basis of an interdisciplinary dialogue between history and sociology, the interweaving of various macro and meso sociopolitical conditions that hamper the processing of this past at a local level, in a period that ranges from the alternation of the party in federal executive power (2000) to the delivery of the final report of the Truth Commission for Guerrero (2014). The research shows that struggles for truth and justice are cut through by a situation of chronic violence, fueled by deep sociopolitical antagonisms, precarious personal security conditions and slow, selective institutional actions.

Key words: chronic violence; impunity; counterinsurgency; truth and justice; Guerrero.

Fecha de recibido: 30 de mayo de 2017 Fecha de aceptación: 12 de octubre de 2017

\section{DESFASES REGIONALES: ENTRE LA ALTERNANCIA Y LA RANCIA VIOLENCIA POLÍTICA}

$\mathrm{L}$ a segunda mitad del siglo xx mexicano se caracterizó por un sostenido agotamiento de los procedimientos legales para garantizar una mayor influencia en las decisiones del gobierno por parte de amplios sectores sociales que buscaban acotar el gran poder político y económico de empresarios y otros intermediarios; concretamente en Atoyac, los acaparadores mantenían en la miseria a gran parte de la población agraria (Radilla, 1998), y recurrían a la violencia física para reprimir, e incluso aniquilar cualquier forma de oposición política (Román, 2007; Radilla y Rangel, 2011). Ello abonó el terreno para la insurrección armada encabezada por el Partido de los Pobres (Bellingeri, 2003), poniendo en la mira de la violencia de Estado a amplios sectores campesinos: de los 450 casos de desaparición forzada ocurridos en Guerrero en la década de 1970, la mayoría procede de este municipio (COMVERDAD, 2014).

Tras las elecciones presidenciales del año 2000 la alternancia política creó expectativas de mejorar la situación de derechos humanos y tramitar políticamente el cruento proceso de aniquilación de opositores políticos que 
ocurrió en México entre las décadas de 1960 y 1980 (Femospr, 2006; Argüello, 2010). Diversas experiencias de procesamiento social, político y judicial de pasados violentos en latitudes como Argentina, Chile, Perú, Guatemala (Dutrénit y Varela, 2010; Barahona, González y Aguilar, 2004), Sudáfrica o Ruanda (Hayner, 2008), evidencian la complejidad de su realización al estar sujetas a múltiples variables y condiciones sociopolíticas. En este sentido, había desfases regionales en relación con los procesos macro políticos que ocurrían en México: Guerrero seguía gobernado por el Partido Revolucionario Institucional (PRI) y Atoyac continuaba convulsionado por conflictos sociales, profundamente impactados por la masacre de Aguas Blancas -ocurrida en Coyuca de Benítez, en 1995-, que desató la proliferación de grupos armados -tanto guerrilleros como paramilitares-, una persistente presencia militar (Gutiérrez, 1998), la persecución de miembros de la Organización Campesina de la Sierra del Sur (ocss), así como la constante represión de campesinos ambientalistas por parte de fuerzas del orden público. ${ }^{1}$

Distintas posibilidades de procesar la "guerra sucia" se barajaron, debido al enjuiciamiento en tribunales militares de los generales Mario Arturo Acosta Chaparro y Humberto Quirós Hermosillo, vinculados con la violencia política de esa época, encarcelados por su complicidad con narcotraficantes desde agosto del año $2000 .^{2} \mathrm{La}$ oportunidad de procesar penalmente al general Acosta Chaparro por desaparición forzada unificó a familiares y a activistas que, a fines de 2001, reunieron 120 denuncias en su contra y atrajeron la atención de la Comisión Nacional de Derechos Humanos (CNDH) para realizar peritajes en Guerrero. ${ }^{3}$ La existencia de grupos guerrilleros, la actividad política de la dinastía Figueroa en la entidad -ligada a la contrainsurgencia y la masacre de Aguas Blancas-y el asesinato de activistas ligados

${ }^{1}$ Las notas periodísticas citadas proceden del archivo personal del profesor Víctor Cardona, cronista municipal de Atoyac de Álvarez, a quien agradezco profundamente el acceso. Véase N. Bello, "Liberan a Miguel Ángel Serafín, uno de los presos políticos de Acapulco", La Jornada, El Sur, 23 de enero de 2000, y V. Cardona, "El pueblo se alarmó por la destrucción y se levantó contra la tala", La Jornada El Sur, 7 de marzo de 2000.

${ }^{2}$ V. Cardona y F. Magaña, "Once campesinos del Rincón de las Parotas fueron desaparecidos en 1973, acusados de ser Guerrilleros”, Atl. Quincenario de Información y Análisis, año 2, núm. 30, 1-15 de octubre de 2000.

${ }^{3}$ V. Cardona, "En Atoyac, reunión plural de familiares de desaparecidos", La Jornada El Sur, 11 de septiembre de 2000; M. Villegas, "Busca la CNDH restos de guerrilleros enterrados en la región de la Pascua”, Atl. Quincenario de Información y Análisis, año 2, núm. 42, 2-15 de abril de 2001; M. Loza, "Entrega AfADEm nuevas denuncias ante la PGR. Atl. Quincenario de Información y Análisis, año 2, núm. 43, 18-30 de abril de 2001. 
a la ocss, ${ }^{4}$ generaban amplios debates sobre qué episodios de violencia política era preciso indagar. Además, algunos actores exigían crear un organismo integrado por personas de proba reputación que estableciera una narrativa histórica fundada en documentación oficial y testimonios, denominada "verdad histórica", en referencia a la Comisión Nacional sobre la Desaparición de Personas (Conader) en Argentina (Crenzel, 2008); el siguiente paso sería procesar judicialmente a los responsables. ${ }^{5}$

En medio de estas discusiones, la CNDH presentó a fines de noviembre de 2001 su Informe 26/2001, documento que reunía -y complementaba- información producida por asociaciones de familiares de desaparecidos desde la década de 1970 -principalmente la Asociación de Familiares de Detenidos Desaparecidos y Víctimas de Violaciones a los Derechos Humanos en México (AfADEM) y el Comité ¡Eureka! (Argüello, 2010) -, y establecía 532 casos de los más de 600 denunciados a nivel nacional. En tal acto el presidente Vicente Fox anunció que se crearía la Fiscalía Especial para la Atención de Presuntos Delitos Cometidos por Servidores Públicos en contra de Movimientos Sociales y Políticos del Pasado (Femospr), instancia dependiente de la Procuraduría General de la República (PGR) facultada para indagar y procesar judicialmente a los presuntos responsables de tales delitos (Dutrénit y Argüello, 2011).

\section{LAS LUCHAS POR EL DEBER DE MEMORIA EN ATOYAC}

Estos procesos estimularon que en Atoyac se exigiera exhumar y analizar los presuntos restos óseos del dirigente guerrillero Lucio Cabañas Barrientos, lo cual inició el 3 de diciembre de 2001, un día después de su 27 aniversario luctuoso. ${ }^{6}$ En mayo de 2002 la Fiscalía Especial abrió una oficina alterna en la cabecera municipal coordinada por Georgina Landa quien, al igual que el fiscal Ignacio Carrillo Prieto, carecía de la confianza de organizaciones atoya-

${ }^{4}$ F. Magaña, "Conmemoran el 18 de mayo de 1967: dos marchas paralelas" Atl. Quincenario de Información y Análisis, año 2, núm. 45, 15-30 de mayo de 2001.

${ }^{5}$ F. Magaña, "Una comisión de la verdad para los desaparecidos políticos: Afadem. Atl. Quincenario de Información y Análisis, año 2, núm. 49, 18-31 de julio de 2001.

${ }^{6}$ F. Magaña y V. Cardona, "Conmemoran en forma separada la muerte de Lucio Cabañas”, Atl. Quincenario de Información y Análisis, año 3, núm. 58, 9-31 de diciembre de 2001. 
quenses por no ser una reconocida experta en materia de derechos humanos. ${ }^{7}$ A fines de agosto de ese año se creó la Coordinadora Lucio Cabañas Barrientos, tras ser identificados positivamente los restos de Lucio Cabañas. Las principales organizaciones locales opositoras al PRI en Atoyac y otras organizaciones estatales y nacionales, ${ }^{8}$ prepararon los funerales del líder guerrillero, ${ }^{9}$ en medio de confrontaciones entre actores locales sobre si tan emblemática figura debía recordarse como profesor rural o como guerrillero campesino. ${ }^{10}$

Los funerales iniciaron el 30 de noviembre de 2002 con el traslado de los restos a la Escuela Normal Rural Raúl Isidro Burgos de Ayotzinapa -su casa de estudios- donde se celebraron homenajes; luego fueron llevados a Chilpancingo, y posteriormente llegaron a San Martín de las Flores, poblado donde yacía la tumba de su madre. El 2 de diciembre se celebró un acto multitudinario para depositar los restos en un monumento ubicado en la Plaza Morelos de Atoyac, mismo que reunió a miembros de organizaciones locales, nacionales y extranjeras vinculadas con las luchas sociales. Así, los restos del guerrillero quedaron frente al antiguo palacio municipal, ${ }^{11}$ en un acto que conjugó simbólicamente tanto el inicio como el final de la "guerra sucia": la Masacre de Atoyac -ocurrida en esa plaza el 18 de mayo de 1967se considera el punto de inicio por representar el acontecimiento que desató la aparición de la guerrilla y el asesinato del profesor Cabañas -ocurrido el 2 de diciembre de 1974-, que marcó el aniquilamiento de la guerrilla. De este modo, colocar un monumento en ese espacio representó un intento por establecer un deber de memoria (Jelin, 2002; Todorov, 2000).

${ }^{7}$ F. Magaña y M. Villegas, "No es garantía el fiscal de la PGR en el caso de los desaparecidos: ocss. Atl. Quincenario de Información y Análisis, año 3, núm. 60, 22-31 de enero de 2002.

${ }^{8}$ F. Magaña, "Los resultados de ADN de los restos de Lucio Cabañas en un mes se darán a conocer: Pablo Cabañas Barrientos”, Atl. Quincenario de Información y Análisis, año 3, núm. 66, 21-30 de abril de 2002.

9 Magaña, "Preparan funerales de LCB. Atl. Quincenario de Información y Análisis, año 3, núm. 77, 15-22 de septiembre de 2002.

${ }^{10}$ M. Loza, "Preparativos para sepultar los restos de LCB en el zócalo de Atoyac", Atl. Quincenario de Información y Análisis, año 4, núm. 82, 17-30 de noviembre de 2002; F. Magaña y F. Fierro, "LCB sepultado en el zócalo de Atoyac", Atl. Quincenario de Información y Análisis, año 4, núm. 84, 4-20 de diciembre de 2002.

${ }^{11}$ F. Magaña y F. Fierro, "LCB sepultado en el zócalo de Atoyac", Atl. Quincenario de Información y Análisis, año 4, núm. 84, 4-20 de diciembre de 2002. 


\section{LA VIOLENCIA POLÍTICA Y LA IMPOSIBILIDAD DE LA FEMOSPP (2003-2006)}

A fines de 2002 las instancias de procuración de justicia estatal reabrieron el Caso Aguas Blancas y ello enrareció el contexto político local, pues Miguel Ángel Mesino -también dirigente de la ocss-fue detenido, acusado de dirigir el Comando Justiciero 28 de Junio -un grupo guerrillero-, rumor que la ocss imputaba al ex gobernador Rubén Figueroa Alcocer..$^{12}$ Ante la falta de excavaciones prometidas por el fiscal,,$^{13}$ en mayo de 2003 la vicepresidenta de AfADEM ${ }^{14}$ gestionó la presencia de miembros del Equipo Argentino de Antropología Forense (EAAF), que llegaron en septiembre a Atoyac para colaborar con la fiscalía. ${ }^{15}$ Para noviembre de 2003 se anunció que Isidro "Chiro" Galeana -jefe de la Policía Judicial durante la etapa contrainsurgente- sería procesado, pero ello no ocurrió pues Zacarías Barrientos -un campesino que actuó como delator y era testigo clave en su contra-fue asesinado el 26 de noviembre, días antes de ratificar su declaración. ${ }^{16}$ Esto profundizó las diferencias entre demandantes y representantes de la Femospp; Tita Radilla -vicepresidenta de AFADEM- responsabilizó a la Fiscalía de no proteger a su testigo, y la Procuraduría General de Justicia de Guerrero (PGJG) detuvo el 7 de enero de 2004 a cuatro familiares de desaparecidos de la época. ${ }^{17}$ Frente a ello diversas organizaciones locales exigieron liberar a los detenidos y que los funcionarios de la fiscalía salieran de Atoyac. ${ }^{18}$ Entre tanto, Tita Radilla

${ }^{12}$ F. Fierro, "Desarticular a la ocss objetivo del gobierno: Hilario Mesino", Atl. Quincenario de Información y Análisis, año 4, núm. 87, 2-15 de febrero de 2003.

${ }^{13}$ A. L. Torres, "Habrá resultados sobre desaparecidos en 90 días, afirma la Fiscalía Especial”, El Sol de Acapulco, 16 de febrero de 2003.

${ }^{14}$ F. Magaña, "El gobierno federal no ha cumplido en el caso de los desaparecidos", Atl. Quincenario de Información y Análisis, año 4, núm. 94, 1-15 de junio de 2003.

${ }^{15}$ Redacción, "Médicos forenses argentinos en posible exhumación de desaparecidos políticos”, Atl. Quincenario de Información y Análisis, año 5, núm. 100, 21-30 de septiembre de 2003.

${ }^{16}$ Redacción, "Ejecutan a un testigo de la Fiscalía sobre los desaparecidos en la Sierra de Atoyac", El Sur, 28 de noviembre de 2003.

${ }^{17}$ F. Magaña, "Protestan por las detenciones en la Fiscalía Especial y el MP de Atoyac", El Sur, 10 de enero de 2004.

${ }^{18}$ F. Magaña, "Dictan formal prisión a los cinco detenidos de Atoyac, y Montaje arbitrario, la resolución del caso de Zacarías, dicen ex presos políticos”, El Sur, 16 de enero de 2004. 
y Rocío Mesino denunciaron hostigamientos por parte de personas desconocidas y miembros de corporaciones policiales. ${ }^{19}$

A partir de 2004 comenzó a afianzarse la política de impunidad: 1) a pesar de las promesas hechas por el fiscal Carrillo Prieto sobre realizar excavaciones en sitios donde potencialmente hubiese fosas clandestinas, ello no ocurrió; 2) el Secretario de la Defensa habló de reconciliación, mientras que la Cámara de Diputados federales aprobó una reforma al artículo 55 del Código Penal federal que concedía prisión domiciliaria a personas mayores de 70 años, algo que posteriormente benefició a personajes como Miguel Nazar Haro $^{20}$-ex titular de la Dirección Federal de Seguridad-. Para 2005 el contexto político estatal se transformó: Zeferino Torreblanca -postulado por el Partido de la Revolución Democrática (PRD) - asumió la gubernatura, ${ }^{21}$ nuevos grupos armados aparecieron en la sierra de Atoyac y el caso de Aguas Blancas tuvo fatales consecuencias como el asesinato de José Rubén Robles Catalán -procurador de justicia durante la administración de Rubén Figueroa Alcocer- en julio de 2005, y el de Miguel Ángel Mesino -dirigente de la ocss en Atoyac- en octubre de ese mismo año. Este escenario se atravesó por el ingreso de una queja interpuesta en 2001 por familiares de Rosendo Radilla Pacheco, desaparecido en agosto de 1974, ante la Comisión Interamericana de Derechos Humanos (CIDH) para emprender un litigio contra el Estado mexicano ante la Corte Interamericana de Derechos Humanos (СоIDH), debido a la falta de resultados de la Femospr. A nivel local, las tensiones entre grupos no armados por sus presuntos vínculos con grupos armados ${ }^{22}$ afectaron la conmemoración del 31 aniversario luctuoso de Lucio Cabañas Barrientos ${ }^{23}$ degradando las relaciones entre activistas.

${ }^{19}$ V. Cardona, "Los presuntos asesinos de Zacarías Barrientos al Cereso de Acapulco", Atl. Quincenario de Información y Análisis, año 5, núm. 106, 20-31 de enero de 2004; F. Magaña, "Denuncia Rocío Mesino que militares la amenazaron de muerte", El Sur, 22 de abril de 2004.

${ }^{20}$ A. Peláez, "Exigen a la Femospp resultados sobre el castigo a responsables de la guerra sucia”, El Sur, 30 de abril de 2004.

${ }^{21}$ F. Magaña, "Desalienta un militar en el gabinete; así no se acaban los grupos subversivos: ocss", El Sur, 1 de abril de 2005.

${ }^{22}$ F. Magaña, "Aparecen en Atoyac las primeras pintas del grupo armado FARP”, El Sur, 25 de octubre de 2005; J. Lofredo, "Guerras íntimas", El Sur, 23 de octubre de 2005.

${ }^{23}$ F. Magaña, "Se disputan en Atoyac el obelisco a Lucio Cabañas para actos por el día de muertos", El Sur, 3 de noviembre de 2005; F. Magaña, "Pleito entre organizaciones en Atoyac en aniversario luctuoso de Lucio Cabañas", El Sur, 3- 4 de diciembre de 2005. 
A principios de diciembre de 2005 el fiscal Carrillo Prieto presentó un informe de actividades en el cual propuso la posibilidad de indemnizar a familiares de víctimas de desaparición forzada en Atoyac. Entre las cuatro agrupaciones coadyuvantes (Afadem, el Comité de Familiares de Desaparecidos de los años setenta, un grupo dirigido por Evaristo Castañón y la Asociación Nacional de Luchadores Sociales), la dirigida por Evaristo Castañón ${ }^{24}$ dispuso recibir recursos económicos desde un inicio, pero en el acto se sumó el Comité de Familiares de Desaparecidos de los años setenta, cuya dirigente (Eleazar Peralta) propuso aceptar las indemnizaciones, sin dejar de buscar a sus familiares. ${ }^{25}$

Tras el escándalo que suscitó la filtración de una versión no autorizada del informe de la Femospp en febrero de 2006, la fiscalía fue desmantelada en abril de ese mismo año sin haber cumplido todos sus objetivos (Dutrénit y Argüello 2011); ante ello, los familiares de Atoyac exigieron a la PGR continuar las investigaciones y tener acceso a los expedientes de las querellas. ${ }^{26}$ Ello estimuló la exigencia de crear una Comisión de la Verdad o de Esclarecimiento Histórico, en momentos en que las movilizaciones de normalistas guerrerenses, la falta de esclarecimiento del asesinato de Miguel Ángel Me$\operatorname{sino}^{27}$ y la presencia de más grupos armados presuntamente guerrilleros en la sierra atoyaquense, ${ }^{28}$ remitían a condiciones de violencia no muy distintas de aquellas que dieron pie a la "guerra sucia". El Informe Final de la FEMOspP tuvo poca difusión y permaneció poco tiempo en la página de internet de la PGR (Dutrénit y Argüello 2011), algo que difirió mucho de lo ocurrido con el Informe de la CONADEP -muy ampliamente difundido entre la población argentina (Crenzel, 2008).

${ }^{24}$ Campesino de El Quemado (poblado de Atoyac cercano al municipio de Coyuca de Benítez, Guerrero) que, como la mayoría de los habitantes varones, fue detenido por el Ejército en 1972 y pasó cinco años en prisión.

${ }^{25}$ F. Magaña, "Propone Carrillo Prieto indemnización por desaparecidos; tres organizaciones de familiares la rechazan", El Sur, 08 de diciembre de 2005.

${ }^{26}$ F. Magaña, "Exigimos a Fox que no se cierren los casos de la Fiscalía, informa Tita Radilla", El Sur, 6 de abril de 2006.

${ }^{27}$ Dirigente de la ocss asesinado en 2005.

${ }^{28}$ F. Magaña, "A un año de la ejecución de Miguel Ángel Mesino, los culpables, sin castigo: ocss", El Sur, 18 de septiembre de 2006; F. Magaña, "Mantas y pintas de grupos armados en el 32 aniversario de la muerte de Lucio en Atoyac", El Sur, 3 de diciembre de 2006. 


\section{EL CASO ROSENDO RADILLA PACHECO Y LA “GUERRA" CONTRA EL NARCO (2007-2011)}

El caso Rosendo Radilla Pacheco impulsó que la PGR diera seguimiento a casos iniciados por la extinta fiscalía, como ocurrió con la identificación positiva de restos óseos hallados en 2005 como pertenecientes a dos campesinos seguidores de Lucio Cabañas, los cuales fueron entregados a sus familiares el 7 de febrero de 2007. ${ }^{29}$ No obstante, la denominada "guerra contra el narcotráfico" emprendida por Felipe Calderón Hinojosa -que reveló una importante penetración de los intereses del narcotráfico en todos los niveles de gobierno (Equipo Bourbaki, 2011) - afectó también a Atoyac, iniciando una oleada de asesinatos de alto impacto: el 9 de febrero de 2007 fue acribillado Germán Adame, ex presidente municipal (2002-2005) de extracción priista acusado de tener vínculos con narcotraficantes. ${ }^{30}$

Además, el general Mario Arturo Acosta Chaparro fue liberado, a pesar de ser sentenciado en noviembre de 2002 a quince años de prisión por narcotráfico pero exonerado por desaparición forzada.${ }^{31}$ Esto ahondó diferencias entre dos organizaciones de familiares: Afadem y el Comité de Familiares de Desaparecidos de los años setenta, pues se acusaba que el testimonio de la dirigente del Comité fue clave para exonerar a Acosta Chaparro. ${ }^{32}$ A nivel local, la confrontación entre dos grandes bloques estatales del PRD produjo fuertes enfrentamientos entre la ocss y el presidente municipal que suscitaron la mediación de los poderes ejecutivo y legislativo estatales. ${ }^{33}$ Aunque el proceso en la CIDH reintrodujo la violencia política pasada en la agenda política a nivel nacional, ciertos factores políticos locales restaron fuerza a los actores demandantes de verdad y justicia como AfADEM, entre los cua-

${ }^{29}$ E. Olivares, “¡Ahí están, lo prometido es deuda!, dice la PGR al entregar osamentas de la guerra sucia”, La Jornada, 11 de febrero de 2007.

${ }^{30}$ F. Magaña, "Detienen a tres hombres como presuntos autores del asesinato del ex alcalde de Atoyac y su madre", El Sur, 11 de febrero de 2007.

${ }^{31}$ M. Martínez, "En el 12 aniversario de Aguas Blancas rechazan la comisión de la verdad”, El Sur, 27 de junio de 2007.

${ }^{32}$ F. Magaña, "Indigna a fundador de la ocss liberación de Acosta Chaparro", El Sur, 2 de julio de 2007; R. Huerta, "Exonerado por la justicia, condenado por el pueblo", La Jornada Guerrero, 5 de julio de 2007.

${ }^{33}$ F. Magaña, "Planta el cabildo de Atoyac al cCP; los campesinos bloquean los accesos a la ciudad", El Sur, 1 de agosto de 2007; H. Pacheco, "Llama el Congreso al presidente municipal Pedro Brito a que explique conflicto”, El Sur, 9 de agosto de 2007. 
les destacó la sostenida campaña de desprestigio y hostigamiento contra la familia Mesino Mesino -fundadora de la ocss en el municipio-, pues contribuyó al desgaste de la ocss, uno de los aliados locales más constantes de AfAdem en pro de las víctimas de desaparición forzada. ${ }^{34}$

Para 2008 en Atoyac aumentó la violencia atribuida al crimen organizado, ${ }^{35}$ concordante con un panorama crítico para los derechos humanos que alcanzó en septiembre las 704 peticiones de casos ocurridos en México ante la $\mathrm{CIDH} ;{ }^{36}$ coincidentemente, el general Acosta Chaparro fue nombrado asesor presidencial. ${ }^{37}$ A nivel local nuevas discordias en torno a la figura de Lucio Cabañas se hicieron patentes durante la conmemoración de su 34 aniversario luctuoso el 2 de diciembre de 2008: se realizaron dos marchas ${ }^{38}$ y la condición de familiar como una fuente de legitimidad para demandar verdad y justicia (Argüello, 2010; Jelin, 2010), se tornó en una senda disputa por el "uso legítimo" de la figura del líder guerrillero.

En el plano estatal, el gobernador Torreblanca fue señalado por proteger a Rogaciano Alba -un narcotraficante aliado del cártel de Sinaloa-, a cuyo servicio había sicarios y paramilitares que asesinaban a quienes se oponían a proyectos empresariales de corte extractivo. ${ }^{39}$ En este contexto la conmemoración del aniversario de la masacre de Atoyac (2009) fue un foro para denunciar la desaparición de líderes campesinos perredistas, el intento de "levantar" a Rocío Mesino por parte de personas armadas, y reivindicar el Caso Radilla Pacheco como un mecanismo para buscar a todos los desaparecidos (El Sur, 19 de mayo de 2009). Mientras el gobernador negaba que la creciente militarización se debiera a la presencia de grupos guerrilleros, ${ }^{40} \mathrm{el}$

${ }^{34}$ A. Solís, "Asegura que en El Escorpión no tienen vínculos con guerrilleros", Despertar de la Costa, 29 de noviembre de 2007.

${ }^{35}$ F. Magaña, "Marcharán mujeres de diversas organizaciones sociales para exigir seguridad en Atoyac”, El Sur, 15 de julio de 2008.

${ }^{36}$ J. Díaz Briceño, "México en el banquillo de la justicia internacional", El Sur, 21 de septiembre de 2008.

${ }^{37}$ E. Olivares, "Es posible aclarar los periodos oscuros del país: Carlos Montemayor", La Jornada, 30 de septiembre de 2008.

${ }^{38}$ J. Reynada, "Recuerdo de Lucio es a todos los luchadores", Despertar de la Costa, 28 de noviembre de 2008.

${ }^{39}$ Z. Cervantes, "La guerrilla está combatiendo a sicarios del narco y paramilitares, dice jefe del ERPI", El Sur, 12 de mayo de 2009; Z. Cervantes, "Descalifica Zeferino al guerrillero que lo acusó de proteger al narco; es un delincuente prófugo, dice”, El Sur, 22 de mayo de 2009.

${ }^{40}$ J. Saavedra, "Sitian 500 militares dos días dos poblados de la sierra para buscar a Ramiro del ERPI”, El Sur, 19 de junio de 2009. 
7 de julio de 2009 se celebró la audiencia ante la CoIdH, en la cual el entonces secretario de Gobernación, Fernando Gómez-Mont, afirmó que México poseía mecanismos para "impedir" las desapariciones forzadas, en tanto que los querellantes aseguraban que las estructuras de impunidad y protección a perpetradores seguían vigentes. ${ }^{41}$

La Corte Interamericana falló el 23 de noviembre de 2009 contra el Estado mexicano por el Caso Rosendo Radilla Pacheco; la sentencia reconoció la violación de diversos derechos de tres familiares de Radilla Pacheco: Rosendo, Tita y Andrea Radilla Martínez, y obligaba al Estado mexicano a determinar las responsabilidades penales, sancionar a quienes resultasen responsables, así como continuar con la búsqueda "efectiva y localización inmediata" de Rosendo Radilla Pacheco, o en su defecto, de sus restos mortales. En materia legislativa, la sentencia exigía a México reformar diversos artículos del Código de Justicia Militar y del Código Penal Federal, a fin de armonizarlos con la Convención Interamericana sobre Desaparición Forzada de Personas y otros estándares internacionales. Además, el Estado debía difundir la sentencia de la Corte, realizar un acto de desagravio en memoria de Rosendo Radilla Pacheco, publicar su semblanza biográfica, dar atención psicológica profesional a las tres víctimas e indemnizarlas, entre otras cosas. ${ }^{42}$

Este fallo tuvo múltiples consecuencias. A nivel microsocial estimuló aún más la fragmentación política de los actores locales demandantes de verdad y justicia, lo cual se hizo evidente al realizarse tres actos para conmemorar el 35 aniversario luctuoso de Lucio Cabañas (2 de diciembre de 2009), siendo constante el llamado de hijos de guerrilleros caídos a las organizaciones sociales para unificarse políticamente y enfrentar la represión, debido a la permanente violencia a la que amplios sectores opositores estaban expuestos. ${ }^{43}$ El 14 de diciembre la CoIDH emitió su sentencia definitiva, ratificando lo dispuesto el 23 de noviembre y obligando a tipificar el delito de desaparición forzada, pues este pendiente contravenía los compromisos con

${ }^{41}$ G. León y A. Muñoz, "Mantiene el Estado su estructura de impunidad, reviran a Gómez Mont hijos de Rosendo Radilla”, La Jornada, 9 de julio de 2009.

${ }_{42}$ Corte Interamericana de Derechos Humanos (2009). Caso Rosendo Radilla Pacheco vs. Estados Unidos Mexicanos. Sentencia de 23 de noviembre de 2009 (excepciones preliminares, fondo, reparaciones y costas). Recuperado de: www.corteidh.or.cr/docs/casos/articulos/seriec_209_ esp.doc

${ }^{43}$ Redacción, "A 35 años de la muerte de LCB", Atl. Quincenario de Información y Análisis, año 11, núm. 165, 15 de diciembre de 2009. 
la Convención Interamericana sobre esa materia y obstaculizó la labor de la Femospr.

Y aunque la sentencia fue aclamada por múltiples organizaciones defensoras de derechos humanos nacionales e internacionales, a nivel local produjo inconformidades y resultados ambiguos para la AfADEM: si bien ello le dio mayor reconocimiento nacional e internacional, la obligación de indemnizar a tres miembros de la familia Radilla Martínez fue problemática para su vicepresidenta, quien sostuvo a lo largo de años que no aceptarían indemnizaciones sin conocer el paradero de sus familiares. También incrementó el encono entre organizaciones de familiares de desaparecidos, lo cual minimizó el carácter ejemplar del Caso Radilla Pacheco. ${ }^{44}$ Además, el cumplimiento de la sentencia era parcial y muy lento, en un contexto de violencia que ubicó a Guerrero en 2010 como la tercera entidad con más alto número de homicidios dolosos en el país, ${ }^{45}$ donde proliferaron denuncias sobre violencia contra opositores políticos y asesinatos atribuidos a la guerrilla. ${ }^{46}$

El 19 y 20 de octubre de 2010 la PGR realizó nuevas excavaciones en Atoyac, en concordancia con la sentencia de la CoIDH, mientras que la Cámara de Diputados aprobó un presupuesto de 30000000 de pesos para cumplir cuatro sentencias de la CoIDH, una de las cuales derivó del Caso Radilla Pacheco; y aunque la vicepresidenta de AfADEM afirmó que no aceptaría pago alguno, la noticia reforzó rumores sobre un presunto favoritismo de las instituciones hacia el caso de su padre. ${ }^{47} \mathrm{Al}$ cierre del año 2010, en Atoyac reinaba la zozobra debido a rumores sobre posibles confrontaciones entre narcotraficantes por el control de la producción y distribución de estupefacientes ${ }^{48}$ por lo que la conmemoración del 36 aniversario luctuoso de

${ }^{44}$ F. Fierro y E. Barrientos, "La medalla a Tita y al Padre Máximo: el lado humano del reconocimiento", Atl. Quincenario de Información y Análisis, año 12, núm. 167, 7 de abril de 2010.

${ }^{45} \mathrm{Z}$. Cervantes, "Guerrero: bajo el influjo de la narco violencia", Trinchera. Política y Cultura, 27 de abril de 2010.

${ }^{46}$ Z. Cervantes, "Tienen Guerrero, Oaxaca y Chiapas los índices más bajos en derechos humanos”, El Sur, 13 de septiembre de 2010.

${ }^{47}$ A. Harrison, "No hay voluntad política del estado para castigar a autores de la guerra sucia: Tita Radilla", El Sur, 19 de octubre de 2010.

${ }^{48}$ D. Arzeta, "Incertidumbre por presunto comunicado de presunto grupo delictivo", Diario Objetivo, 22 de noviembre de 2010. La ruptura entre el Cartel de Sinaloa y los Beltrán Leyva ocurrida en 2010 explica el repunte de la violencia entre organizaciones criminales regionales, aunque otras dinámicas más específicas de Atoyac y la Costa Grande ligadas a las alianzas de los "San Luises" de Tecpan de Galeana con La Familia Michoacana permiten entender lo que ocurrió a nivel local (Argüello, 2016). 
Lucio Cabañas ocurrió en momentos muy adversos para las movilizaciones sociales: cinco actos tuvieron lugar, y en los últimos dos Tita Radilla intervino sin marchar en alguno, probablemente para distanciarse de las disputas políticas coyunturales. ${ }^{49}$

El Caso Radilla Pacheco registró avances a mediados de 2011, cuando la Suprema Corte de Justicia de la Nación (scjN) acotó el fuero militar, estableciendo que cualquier violación de derechos humanos de militares contra civiles debía ser juzgada por civiles..$^{50}$ En Atoyac se realizó el 15 de diciembre una ceremonia para develar una placa conmemorativa de la desaparición de Rosendo Radilla Pacheco y contó con la presencia del "encargado de la oficina” de la Secretaría de Gobernación, la titular de la Secretaría de Relaciones Exteriores, el entonces gobernador Ángel Aguirre Rivero y el alcalde Carlos Armando Bello. Tal acto motivó controversias, expresadas mediante la ausencia de la familia Radilla Martínez y la protesta de Eleazar Peralta, quien exigió presentar a todos los desaparecidos y dar trato igualitario a todos los familiares. ${ }^{51}$

\section{LA COMVERDAD Y LA CRECIENTE VIOLENCIA EN ATOYAC (2012-2014)}

Otra consecuencia del Caso Radilla Pacheco fue el envío que hizo el gobernador Aguirre de una iniciativa de Ley para crear la Comisión de la Verdad de Guerrero (Comverdad) en noviembre de 2011, la cual fue discutida y promulgada en el Congreso estatal hasta principios de 2012. La denominada Ley 932 estableció que la COMVERDAD duraría 24 meses, tendría un presupuesto asignado por el Congreso, gozaría de autonomía de gestión, y tendría el mandato jurídico para acceder a información y archivos de las diversas instituciones de los tres órdenes de gobierno. Entre sus principales objetivos estaban el establecer un relato que pudiese sustentar posteriores acciones ju-

${ }^{49}$ F. Magaña, "Cinco actos y dos marchas en el 36 aniversario de la muerte de Lucio Cabañas", El Sur, 03 de diciembre de 2010.

${ }^{50} \mathrm{~J}$. Carrasco, "En atención a recomendación de la CoIDH por el caso Radilla, acota la Corte fuero militar", El Sur, 7 de julio de 2011.

${ }^{51}$ F. Magaña, "Sin familiares de Rosendo Radilla, devela SEgob placa para rememorar al desaparecido" El Sur, 18 de noviembre de 2011. 
diciales de las respectivas instancias sobre el periodo de 1969 a 1979 y emitir recomendaciones en materia de reparación y no repetición.

A diferencia de la Femospp, la Comverdad fue encabezada por cinco comisionados cuyos perfiles eran ampliamente conocidos por quienes demandaban verdad y justicia: su comisionado presidente fue Enrique González Ruiz, abogado, académico, activista y ex rector de la Universidad Autónoma de Guerrero (UAGRo). Por su parte, el doctor Arquímedes Morales y Nicomedes Fuentes García estaban también ligados a la UAGRO: uno también como ex rector y el otro como activista estudiantil y ex preso político en la década de 1970. Las comisionadas restantes eran dos mujeres con experiencia en la defensa de derechos humanos: Hilda Navarrete Gorjón, originaria de Coyuca de Benítez, quien asesoró a ejidatarios de Atoyac durante conflictos con compañías madereras entre 1999 y 2008; y finalmente, Pilar Noriega, abogada con una sólida trayectoria en la defensa de derechos humanos desde la década de 1980 en México. Cuatro comisionados estaban íntimamente vinculados con la región, y ello los expuso a cuestionamientos sobre su parcialidad en favor de las víctimas, aunque su nombramiento expresaba las dinámicas políticas a nivel estatal. No obstante, un perfil de amplio compromiso con las demandas de verdad y justicia resultó ser mejor recibido entre testigos y víctimas.

Para lograr sus objetivos, la Comverdad conformó dos grandes equipos: uno encargado de la investigación documental y otro que realizaría el trabajo en campo recabando testimonios y encabezando excavaciones. El presupuesto total asignado por el Congreso (20 000000 de pesos) se destinó al pago de honorarios y gastos de quienes hacían trabajo en campo y en el Archivo General de la Nación (AGN), a la renta de dos oficinas (una en Acapulco, y la otra en Chilpancingo) y a la adquisición de tres vehículos automotores. Cuando la Comverdad inició sus trabajos en Atoyac enfrentó múltiples dificultades: por un lado, eran patentes las profundas discordias entre asociaciones de familiares de víctimas de desaparición forzada, pues algunas priorizaban la indemnización económica por encima de la persecución judicial de los responsables o del hallazgo de los restos de sus familiares. Por otro lado, el estatus de "víctima de la guerra sucia" se amplió gracias a que el discurso vinculado con los derechos humanos fue el principal hilo para interpretar un pasado violento, lo cual hizo plausible acceder a reparaciones económicas. Así, los desaparecidos y sus familiares dejaron de ser las únicas víctimas "legítimas", y esta condición se extendió hacia sobrevivien- 
tes de desaparición forzada, algo reconocido en la sentencia de la CoidH. ${ }^{52}$ Además, las condiciones de seguridad pública a nivel nacional y local eran bastante adversas para generar mejores expectativas sobre justicia: la Operación Guerrero Seguro ${ }^{53}$ se extendió a la Costa Grande, Tierra Caliente y la región Centro en marzo de 2012, incrementando los niveles de violencia y abusos contra la población civil. ${ }^{54}$

A este panorama las elecciones federales para designar presidente de la república, senadores y diputados federales ${ }^{55}$ añadieron más complejidad. Además, en abril de 2012 fue asesinado el general Acosta Chaparro, sin haber rendido testimonio sobre su participación en la contrainsurgencia y persecución de opositores políticos en los años setenta y ochenta. ${ }^{56}$ Otro personaje ligado a esa época de gran trascendencia en Atoyac, Octaviano Santiago Dionisio, también falleció el 9 de agosto de 2012, lo cual resultó problemático para la COMVERDAD, pues él era uno de los principales enlaces a nivel local. ${ }^{57}$ Esto hace comprensible que los comisionados mantuvieran el anonimato de los testimonios que sólo podían ser rendidos ante ellos, pues eran quienes gozaban de fe pública. En el caso de los trabajos de corte documental había grandes trabas por parte de la PGR, pues la instancia mantenía la "reserva" de los documentos recabados por la Femospr, resguardados en una bóveda especial del AGN. ${ }^{58}$ Otros procesos que se entrecruzaban con los trabajos de

${ }^{52}$ Rompeviento TV, La guerra sucia y la Comisión de la Verdad de Guerrero, en De Este Lado. Rompeviento TV, 15 de septiembre de 2014. [video de Youtube consultado el 16 de septiembre de 2014]. Recuperado de https://www.youtube.com/watch?v=qKvNqKvplZ8

${ }^{53}$ Entre 2007 y 2012 el gobierno federal desplegó más de 7000 efectivos federales, entre militares, marinos y policías federales, en distintas fases y regiones del estado de Guerrero, para combatir el crimen organizado. Específicamente la Operación Guerrero Seguro (sucesora de la Operación Conjunta Guerrero, principalmente destinada a Acapulco), arrancó en octubre de 2011, con más de 2000 elementos federales, véase D. Velázquez, "Guerrero cierra el sexenio de Calderón con 4 mil 641 asesinatos, sólo después de Chihuahua y Sinaloa”, El Sur, 1 de diciembre de 2012.

${ }^{54}$ M. Labastida, "Se ampliará Guerrero seguro a Tierra Caliente, Costa Grande y Centro, anuncia Aguirre Rivero”, El Sur, 19 de marzo de 2012.

${ }^{55}$ Redacción, "El PRI, responsable de la guerra sucia de las décadas de los 60s y 70s: Pablo Solís”, Atl. Quincenario de Información y Análisis, año IV, núm. 190, 13 de junio de 2012.

${ }^{56}$ Redacción, "Ejecutan en el DF al general retirado Mario Arturo Acosta Chaparro", El Sur, 21 de abril de 2012.

${ }^{57}$ F. Magaña, "Recomiendan a la Comisión de la Verdad rescatar el testimonio de Octaviano Santiago Dionisio”, El Sur, 18 de agosto de 2012.

${ }^{58}$ F. Magaña, "Aún no accede la Comisión de la Verdad a archivos de la PGR, dice en Atoyac", El Sur, 22 de octubre de 2012. 
la Comverdad estaban vinculados con el ámbito federal, pues entre septiembre y noviembre ocurrieron varios anuncios: la PGR definió indemnizar a familiares de 26 desaparecido $s^{59} y$, debido a la reciente promulgación de una Ley General de Víctimas, ${ }^{60}$ la Secretaría de Gobernación (SEgoB) canalizó al Comité Pro Víctima al resto de familiares no indemnizados por la PGR. ${ }^{61}$

Todo ello produjo que el cierre del año 2012 estuviera marcado por reiterados desencuentros entre grupos de familiares, reforzados al publicarse que Eleazar Peralta se había reunido con el entonces diputado local Rubén Figueroa Smutny -nieto de Rubén Figueroa Figueroa, gobernador de Guerrero entre 1975 y $1981 .^{62}$ En 2013 hubo otros avances en el Caso Radilla Pacheco impulsados desde la federación, como la presentación de la semblanza biográfica de Rosendo Radilla Pacheco ocurrida el 1 de marzo de 2013, donde el entonces secretario de gobernación Miguel Ángel Osorio Chong hizo un llamado a "no estancarnos en el pasado". Para la Comverdad hubo nuevas dificultades al abrirse un frente de desprestigio encabezado por un grupo de presuntos voceros de familiares, que acusaba a los comisionados de no emplear sus recursos de operación para indemnizar a las víctimas; señalaba también que la Comisión sólo transcribía el Informe 26/2001 de la CNDH y afirmaba desconocer a los comisionados, por lo cual exigía su remoción. ${ }^{63}$ El comisionado Nicomedes Fuentes respondió que tales acusaciones procedían de la ignorancia y la mala fe, algo que ciertos diarios atribuyeron al ex gobernador Rubén Figueroa Alcocer. ${ }^{64}$ Esto generó que legisladores priistas

${ }^{59}$ F. Magaña, "Inicia la PGR la reparación del daño a familiares de desaparecidos en Atoyac", El Sur, 27 de septiembre de 2012.

${ }^{60}$ Originalmente se promulgó por el senado en abril de 2012, pero tras múltiples controversias fue decretada por el ejecutivo federal el 9 de enero de 2013, configurando un andamiaje jurídico para atender a víctimas de delitos y de violaciones de derechos humanos; entre otras cosas estableció la creación de la Comisión Ejecutiva de Atención a Víctimas; véase Decreto por el que se expide la ley general de víctimas. Diario Oficial de la Federación, 9 de enero de 2013. Recuperado de: http://www.diputados.gob.mx/sedia/biblio/prog_leg/018_DOF_09ene13.pdf

${ }^{61}$ F. Magaña, "Abrirá PGR nuevas listas de familiares de desaparecidos para indemnizarlos”, El Sur, 26 de octubre de 2012.

${ }^{62}$ R. Ramírez, "Se reúne Figueroa Smutny con organización de familiares de víctimas de la guerra sucia”, El Sur, 19 de diciembre de 2012.

${ }_{63}$ M. Labastida, "Piden víctimas de la guerra sucia que se reparta entre ellos el dinero destinado a la Comverdad", El Sur, 11 de marzo de 2013.

${ }^{64}$ A. Silva, "Rubén Figueroa está detrás de las críticas a Comverdad, acusan", Diario Objetivo, 13 de marzo de 2013. 
locales exigieran a la COMverdad no politizar su investigación. ${ }^{65}$ En días posteriores a esta controversia Rocío Mesino -líder de la ocss- fue detenida por homicidio calificado y liberada días después por falta de pruebas ${ }^{66}$ Ello marcó el contexto en que la Comisión presentó su informe parcial el 17 de abril de 2013 en el recinto legislativo estatal, destacando que documentó más casos de ejecuciones extrajudiciales, por lo cual era necesario corregir la cifra de desaparecidos de esa época. Dado que la PGR continuaba sin quitar la reserva a los documentos recabados por la Femospr, la Comisión interpuso un amparo para lograr su consulta. ${ }^{67}$

A mediados de 2013 la violencia desatada durante el sexenio anterior convulsionaba a municipios de Michoacán y de la Costa Grande de Guerrero, uno de cuyos signos fue el surgimiento de grupos civiles de autodefensa armada, cuya posible emergencia circulaba como rumor en Atoyac, pues ya ocurría en el vecino municipio de Tecpan de Galeana.$^{68}$ Una aguda crisis de gobernabilidad, evidenciada a través de la rapidez y alcance de la extensión del fenómeno de las autodefensas en el territorio guerrerense ${ }^{69}$ posiblemente motivó que los comisionados llamaran a las asociaciones de familiares a unificarse y dejar a un lado sus diferencias políticas. ${ }^{70}$ La creación del Comité Pro Víctima -posteriormente transformado en la Comisión Ejecutiva de Atención a Víctimas- era producto de una generalización de la violencia, ante las masivas denuncias de nuevas desapariciones atribuidas al crimen organizado en el país. ${ }^{71}$ Este Comité se presentó en Atoyac a principios de agosto por gestiones de grupos inconformes con la COMVERDAD y con el

${ }^{65}$ A. Silva, "Vicario defiende a Figueroa de críticas de Comverdad", Diario Objetivo, 14 de marzo de 2013.

${ }^{66}$ Y. Trujillo, "No habrá demanda contra la PGJE por la detención, dice el abogado de Rocío Mesino", El Sur, 22 de marzo de 2013.

${ }^{67}$ R. Ramírez, "Documenta la Comverdad cuatro ejecuciones en la guerra sucia, cuando el Ejército sitió el estado", El Sur, 18 de abril de 2013.

${ }^{68}$ F. Magaña, "Crearán en Tecpan una Policía Rural Estatal luego del bloqueo de la autodefensa que duró 30 horas", El Sur, 22 de junio de 2013.

${ }^{69}$ Z. Cervantes, "Ocupan la mitad del estado en dos años las autodefensas ciudadanas ante la violencia”, El Sur, 25 de julio de 2013.

${ }^{70}$ D. Velázquez, "Que los familiares de los desaparecidos se unan en una demanda, llama la Comverdad a los afectados", El Sur, 26 de junio de 2013.

${ }^{71}$ De acuerdo con Merino, Zarkin y Fierro (2015), se publicaron cifras oficiales en 2013 y en 2014; las segundas resultaron de una "depuración", al cotejarse con registros estatales de personas localizadas vivas o muertas, y arrojaron que 12930 personas desaparecieron entre 2006 y 2012, en todos los estados del país. 
presunto favoritismo de las instituciones hacia Afadem. ${ }^{72}$ Paralelamente repuntaban los homicidios cometidos por sicarios en importantes avenidas de la cabecera municipal, ${ }^{73}$ el asesinato de líderes sociales,${ }^{74}$ la encarnizada persecución de policías comunitarios y los desplazamientos forzados de civiles en municipios cercanos. ${ }^{75}$ En este contexto, la COMVERDAD presentó otro informe parcial el 17 de octubre de 2013 en Chilpancingo, denunciando que continuaban las trabas para acceder a la documentación. ${ }^{76}$

Días después de tal presentación, en Atoyac fue asesinada Rocío Mesino (ocss) el 19 de octubre mientras supervisaba un comedor comunitario para la construcción de un puente provisional hacia comunidades que quedaron incomunicadas a raíz del huracán Manuel, que dificultó durante meses los trabajos de la ComverdaAD. ${ }^{77}$ Esta situación sembró la zozobra, pues se rumoraba que el móvil del asesinato era político, contrario a la principal línea de investigación de la Procuraduría Estatal. ${ }^{78}$ Posiblemente ello estimuló la unificación de seis de las siete organizaciones de familiares y víctimas para crear el Comité General Representativo de Víctimas de la Guerra Sucia, que en noviembre de 2013 se pronunció en favor de una iniciativa de ley propuesta por diputados locales para realizar una reparación integral a las víctimas que incluiría: un hospital regional, una institución de educación superior y programas de atención médica y psicológica. ${ }^{79}$ Las condiciones de seguridad empeoraron: el 17 de noviembre de 2013 dos importantes líderes comunita-

${ }^{72}$ F. Magaña, "Envía el gobierno federal médicos y psicólogos a Atoyac para atender a víctimas de la guerra sucia”, El Sur, 1 de agosto de 2013.

${ }^{73}$ F. Magaña, "Matan en Atoyac al dueño de un autolavado y a un comerciante. Asesinan al hermano de un ex coordinador de CECAFE en la Sierra de Atoyac; hieren a un menor", El Sur, 2 de agosto de 2013.

${ }^{74}$ F. Magaña, "Ejecutan en Atoyac a dos comisarios; van cuatro asesinatos de autoridades de la sierra", El Sur, 21 de agosto de 2013.

${ }^{75} \mathrm{Z}$. Cervantes, "Están desaparecidos 70 policías comunitarios que fueron desarmados en Cruz Grande: CRAC”, El Sur, 30 de agosto de 2013.

${ }^{76}$ L. Chávez, "Preocupa a la Comverdad presencia del Ejército y la Marina en las calles”, El Sur, 31 de agosto de 2013; Redacción, "Rubén Figueroa ordenó desaparecer a estudiantes de la UAG: ComverdaD”, Diario Objetivo, 18 de octubre de 2013.

${ }^{77}$ F. Magaña, "Construyen un puente provisional para la comunidad serrana de Pie de la Cuesta, Atoyac", El Sur, 19 de octubre de 2013; F. Magaña, "Asesinan a la dirigente de la ocss Rocío Mesino frente a su familia”, El Sur, 20 de octubre de 2013.

${ }^{78}$ F. Magaña, "Rechaza la familia Mesino la versión oficial de que el asesinato está relacionado con el crimen organizado", El Sur, 23 de octubre de 2013.

${ }^{79}$ F. Magaña, "Unió a familiares de desaparecidos de Atoyac la demanda de reparación integral del daño", El Sur, 18 de noviembre de 2013. 
rios de El Paraíso fueron asesinados por un sicario en pleno centro de Atoyac, precisamente un día antes de crear una policía comunitaria, asesorados por la Unión de Pueblos y Organizaciones del Estado de Guerrero (UPOEG), una organización calificada por Figueroa Smutny como "guerrilla tolerada". ${ }^{80}$

El clima general de violencia en toda la entidad fomentó que la conmemoración del 39 aniversario luctuoso de Lucio Cabañas se diera en Chilpancingo, donde campesinos, profesores, estudiantes y policías comunitarios exigieron a los tres órdenes de gobierno cesar y castigar los homicidios de opositores políticos. ${ }^{81} \mathrm{El} 12$ de enero de 2014 se celebró una reunión entre familiares y representantes del gobierno federal que fue gestionada por la COMVERDAD, en la cual se acordó crear un fideicomiso para indemnizar a familiares de 275 víctimas guerrerenses reconocidas en el Informe 26/2001 de la CNDH; el resto de las víctimas deberían llenar su "formulario" ante la Comisión Ejecutiva de Atención a Víctimas. Esto suponía que, por un lado, más de un centenar de víctimas de la "guerra sucia" harían trámites ante un órgano creado para atender las desapariciones recientes. Por otro lado, se evidenciaba que las propias autoridades federales desconocían la validez del informe de la Femospr, que arrojó más de 400 casos de desaparición forzada en Guerrero. ${ }^{82}$

Ante la necesidad de explorar más pistas para realizar excavaciones y la restricción para acceder a los documentos reservados por la PGR, los comisionados iniciaron la gestión de una prórroga ante el Congreso estatal para proseguir sus trabajos por seis meses más; en tal contexto, el 28 de enero de 2014 Pilar Noriega y Nicomedes Fuentes fueron objeto de un intento de atentado contra su integridad personal mientras circulaban en una carretera del municipio de Iguala. ${ }^{83}$ Pilar Noriega expuso esto en la audiencia de la CIDH

${ }^{80}$ Se trató de José Luis Sotelo y Juan Lucena, véase F. Magaña, "Los dos líderes ejecutados encabezaban la formación de la Policía Comunitaria en El Paraíso, confirman”, El Sur, 18 de noviembre de 2013; L. Chávez, "Asesinan a los líderes de El Paraíso un día antes de formar la autodefensa, dice Bruno Plácido", El Sur, 21 de noviembre de 2013; A. Harrison y D. Velázquez, "La policía comunitaria y la upoeg, 'guerrilla tolerada', califica Figueroa Smutny", El Sur, 21 de agosto de 2013.

${ }^{81}$ L. Chávez, "Marchan 5 mil maestros y activistas en la capital; buscan 'contener la hostilidad' del gobierno", El Sur, 3 de diciembre de 2013.

${ }^{82}$ F. Magaña, "Recibirán reparación del daño 275 familiares de víctimas de la guerra sucia en Atoyac", El Sur, 13 de enero de 2014.

${ }^{83} \mathrm{Z}$. Cervantes, "Sufren agresión en la carretera a Iguala dos integrantes de la Comisión de la Verdad", El Sur, 30 de enero de 2014. 
para defensores de derechos humanos (Washington, 25 de marzo de 2014), donde también informó que los 364 testimonios recabados permitían establecer más sólidamente 450 casos de desaparición forzada únicamente en Guerrero; también denunció otras formas de hostigamiento contra los comisionados y sus colaboradores, además de la continua negativa de la $\mathrm{PGR}^{84}$ para dejarlos consultar los documentos resguardados ${ }^{85}$ y exigió plenas garantías para realizar sus trabajos. ${ }^{86}$

En vísperas de presentar su último informe parcial de labores, la CoMVERDAD solicitó al Congreso estatal un presupuesto de 6000000 de pesos adicionales para operar por seis meses más, en momentos en que volvía a ser objeto de ataques por parte del dirigente del Auténtico Comité General de Desaparecidos, Familiares, Víctimas y Ofendidos de la Guerra Sucia en Atoyac. ${ }^{87}$ Esta solicitud fue rechazada por el Congreso en días posteriores al hallazgo de los restos de un combatiente seguidor de Lucio Cabañas, ocurrido el 15 de junio en el cerro del Posquelite, en el vecino municipio de Coyuca de Benítez. Dada esta situación, los comisionados y parte del personal trabajaron sin retribución para concluir la redacción del informe final, y buscar restos de desaparecidos en diversas zonas del ex cuartel militar de Atoyac. Esto último ocurrió durante el mes de agosto de 2014 con apoyo de peritos de la Comisión de Derechos Humanos del Distrito Federal (CDHDF), sin obtener resultados positivos. ${ }^{88}$

Por su parte, la familia Mesino Mesino (ocss) volvió a ser hostigada: el 4 de septiembre el chofer de Norma Mesino fue detenido, acusado de ser el homicida de su hermana Rocío Mesino; la dirigente de la ocss denunció la falta de avances en la investigación y la protección oficial de los autores materiales e intelectuales.$^{89} \mathrm{El}$ ambiente político local y estatal se enrareció al

${ }^{84}$ Z. Cervantes, "Obstaculiza el Estado mexicano el trabajo de la COMVERdAD, denuncian ante la CIDH", El Sur, 28 de marzo de 2014.

${ }^{85}$ Comisión Interamericana de Derechos Humanos. México: Comisión de la Verdad de Guerrero (video de Youtube consultado el 27 de marzo de 2014). Recuperado de https://www. youtube. $\mathrm{com} /$ watch?v=4QoAYmw8Kgs

${ }^{86}$ L. Chávez, "Amenazan a una integrante de la Comverdad y les roban una camioneta oficial, denuncian", El Sur, 1 de abril de 2014.

${ }^{87}$ P. Solís, "PRD abandona a víctimas de la guerra sucia, denuncian”, Diario Objetivo, 19 de marzo de 2014.

${ }^{88}$ V. Cardona, "Descartan que sean humanos los restos óseos hallados en el ex cuartel militar de Atoyac", El Sur, 29 de agosto de 2014.

${ }^{89}$ F. Magaña, "Detienen a chofer de Norma Mesino por homicidio de su hermana Rocío Mesino”, El Sur, 5 de septiembre de 2014. 
ocurrir la desaparición de 43 estudiantes normalistas de la Escuela Normal Rural Raúl Isidro Burgos de Ayotzinapa, la noche del 26 y madrugada del 27 de septiembre de 2014 en Iguala; tal suceso visibilizó la red de complicidad, el profundo nivel de interpenetración del crimen organizado y las autoridades de gobierno, así como la existencia de fosas clandestinas en Iguala y otros municipios de esa región. Una de sus consecuencias inmediatas fue oscurecer un tema que sería materia de confrontación electoral y fuente de desprestigio para el PRI: la "guerra sucia" de los años setenta. Así, la presentación de una versión preliminar del informe final (ocurrida el 15 de octubre) fue un acto protocolario, al que sólo acudió el presidente de la comisión de gobierno de la Cámara de Diputados estatal a recibirlo. Ahí los miembros de la ComVERDAD lamentaron los hechos de Iguala, adelantando que el informe se basaba en aproximadamente 8000 documentos y más de 300 testimonios, e incluía una lista de perpetradores y recomendaciones al Estado mexicano en materia de reparación y no repetición. Actualmente algunos ex comisionados continúan realizando gestiones para apoyar demandas de víctimas. En este contexto, la celebración del 40 aniversario luctuoso del profesor Cabañas estuvo muy centrado en la demanda de presentar a los 43 desaparecidos, lo cual le dio un carácter multitudinario (Argüello, 2016).

\section{ENTRE EL MIEDO Y LAS EXPECTATIVAS: ALGUNOS APUNTES SOBRE LOS PASADOS QUE NO PASAN}

Haciendo un balance entre la Femospr y la Comverdad, para algunos sobrevivientes de desaparición forzada oriundos de El Quemado, el que Nicomedes Fuentes fuera comisionado les generaba más confianza hacia la Comisión, pues convivieron con él durante su reclusión en un penal de Acapulco, tras ser trasladados de los centros de detención clandestina donde fueron torturados. Es decir, había un nivel de empatía necesario para asumir un compromiso mutuo, a diferencia de los representantes de la Femospp, cuyas trayectorias no eran muy próximas a las experiencias denunciadas por ellos. Por otro lado, el anonimato de los testimonios establecía una relación muy distinta a la que supone tomar declaraciones para integrar procesos penales: en un contexto de vigencia del "Estado de derecho" probablemente habría sido distinta la disposición de los testigos, pero no en las circunstancias fácticas. 
Ahora bien, las evaluaciones sobre los resultados de la COMVERDAD se vinculan con nociones de justicia que entrañan expectativas específicas. Por ejemplo, para agrupaciones como AfADEM o la ocss, "justicia" comprendía tanto el reconocimiento público de lo acontecido -con un consecuente deber de memoria y dignificación simbólica y material de las víctimas-, la sanción penal a los responsables - con la consecuente realización de juicios-y la garantía de no repetición -no sólo al castigar a los responsables, sino estableciendo leyes y mecanismos efectivos para evitar que los hechos se repitieran (Goti, 2000; Nino, 1997; Todorov, 2000). Esta postura estaba mediada por nociones más legalistas y es la que organizaciones defensoras de derechos humanos a nivel nacional e internacional sostienen, pero es minoritaria en Atoyac.

Una segunda posición se anclaba en las condiciones de posibilidad, considerando la imposibilidad de juzgar a los responsables, tanto por la muerte de los señalados, como por las condiciones políticas adversas. Lo "justo" era dignificar a las víctimas tanto simbólica como materialmente, mediante un reconocimiento de lo padecido y reparaciones de tipo financiero o en especie. Esta postura tenía matices alrededor de construir y difundir un relato histórico: para algunos lo único importante era obtener reparaciones económicas, pues "todos sabían lo que había pasado" como en El Quemado - un poblado serrano que actualmente tiene alrededor de 1000 habitantes-, donde no quedó un solo habitante varón mayor de quince años tras las masivas detenciones que realizó el ejército en marzo de 1972. Gran parte de esas tragedias se vivían como un estigma que era mejor olvidar, aunque había quienes dentro de una misma familia demandaban saber "la verdad", como algunos jóvenes nacidos en las décadas de 1980 y 1990. En mucho esto es atribuible a que ni los propios sobrevivientes de desaparición forzada se explicaban cómo una comunidad tan pequeña recibió tal "castigo" por parte del "gobierno", y eso expresaba hasta cierto punto que las experiencias grupales y comunitarias no estaban insertas en un proceso más amplio que permitiera darles un sentido mejor estructurado y facilitara su comprensión (Stern, 2000). En este sentido, se hacía patente la inexistencia de estos procesos traumáticos en el discurso histórico oficial (Aróstegui, 2004).

Una tercera posición afirmaba la inutilidad de un procesamiento público e institucional del pasado violento, porque la FeMOSPP, la PGR y la Comverdad tenían intereses inconfesables y "lucraban con el dolor de los familiares". Quienes la enunciaban tendían a ubicarse políticamente como militantes del PRI o del Partido Acción Nacional (PAN) y consideraban nece- 
sario indemnizar a los familiares de los militares caídos, pues ellos cumplían su deber; los más radicales responsabilizaban totalmente a la guerrilla, pues la violenta respuesta por parte del Estado era "previsible". Una vertiente más matizada -enunciada por personas más jóvenes, también de filiación priista- consideraba adecuado indemnizar a las víctimas, siempre y cuando dieran por terminada la exigencia de conocer el paradero de los desaparecidos, porque era indispensable olvidar, pues "ya pasó y hay que seguir adelante", como si el recuerdo en sí mismo produjera un estancamiento en el pasado, algo coincidente con el discurso que pronunció Osorio Chong cuando afirmó que el Caso de Rosendo Radilla Pacheco "pertenecía al pasado y no debemos estancarnos en él". Lo que esta postura omite es que el pasado no se ha ido jamás (Pécaut, 2000; Theydon, 2004): está presente en el trauma corporizado en los gestos (Dickson-Gómez, 2002), en el temor al activismo, en la desconfianza entre vecinos (Argüello, 2016), en la violencia de Estado cotidiana, en las nuevas masacres, en las nuevas desapariciones, encarcelamientos, ejecuciones o secuestros. Está también presente en el estigma social de ser familiar de un desaparecido (Vázquez, 2003).

Ahora bien, tal posición entraña una noción del poder político como algo que no puede cuestionarse más que al precio de la vida misma, en una relación soberana de exterioridad entre gobernantes y gobernados (Foucault, 1980 y 1990), traducida en masacres, golpizas, detenciones, encarcelamientos, desapariciones, asesinatos y no reconocimiento de las demandas sociales como legítimas. En este sentido, existe una correlación entre las formas concretas que cobran las relaciones y asimetrías de poder, y las posibilidades de procesar pasados violentos traumáticos.

\section{ALGUNAS CONCLUSIONES}

El procesamiento institucional y social del pasado violento en Atoyac ha sido sumamente accidentado, y evidencia diversas consecuencias de la socialización en contextos de violencia crónica (Feldman, 1995) a la que han estado expuestos sus pobladores durante un arco temporal que trasciende al periodo de la "guerra sucia". Pero también revela la compleja imbricación de diversas condiciones que moldearon un proceso que formalmente arrancó en el año 2001. Destacan cuatro, algunas vinculadas con niveles meso y macro sociopolíticos y otras más ancladas en dinámicas micro sociopolíticas. 
En primera instancia, la alternancia de partidos políticos abrió una especie de "caja de pandora" al proponer indagar procesos profundamente traumáticos en Atoyac, sin que hubiese tenido lugar una verdadera ruptura del orden sociopolítico que los produjo (Goti, 2000). Ello supuso la prevalencia de agentes y prácticas "pasadas", cuya vigencia produjo una sistemática obstaculización desplegada desde las propias instituciones involucradas en la búsqueda de verdad y justicia, sea a través de la inacción, la retención de documentación, la falta de herramientas adecuadas para atender las demandas de víctimas y familiares, o de estrategias de intimidación como la presencia de militares o personas no identificadas. Todo eso revela la compleja red de intereses tejida durante las últimas cuatro décadas, inserta en los tres niveles de gobierno, pero también vinculada con diversos sectores sociales, lo cual choca constantemente con intentos de combatir la impunidad.

En segundo lugar, las grandes divergencias entre lo que se considera "justo" o "necesario" para procesar dicho pasado están profundamente ancladas en antagonismos políticos derivados de una violencia estructural que entraña un no reconocimiento de los sectores subordinados como sujetos políticos ni como sujetos de derechos (Honneth, 2009; Wacquant, 2012), así como en procesos de estigmatización de las víctimas y en encarnizadas luchas por validar lo vivido (Schwarzstein, 2001), lo cual se traduce en la fragmentación política de los actores demandantes, en mucho desatada por la posibilidad de acceder a indemnizaciones individualizadas. Ello nos lleva a la tercera situación: la actuación de las instituciones de justicia, que han abordado de forma selectiva, lenta y desigual tales demandas. Ello se expresa en el Caso Rosendo Radilla Pacheco, cuyo pretendido carácter ejemplar se diluyó ante las disputas e intereses políticos -algunos profundamente contrarios a la verdad y la justicia-que debilitaron a los actores demandantes de verdad y justicia en el plano local.

Por último, el caso de Atoyac revela también el impacto de las condiciones de constante violencia a la que están sujetos cada vez más sectores de la población, al no permitir trazar un borde claro entre el pasado y el presente, pues el síntoma de la violencia crónica es precisamente la percepción de una violencia sin fin, continua. La sostenida impunidad y la adición de nuevos episodios violentos entraña una yuxtaposición de temporalidades y agravios que permite entender las constantes y encarnizadas disputas por los contenidos de conmemoraciones que han sido generalmente marginadas del discurso oficial (Catela, 2003). Esto es muy evidente en la conmemoración de 
los aniversarios luctuosos de Lucio Cabañas, que a lo largo de este periodo fue pluralizando sus contenidos -evidenciando su carácter de "lugar de memoria" (LeGoff, 1991)-, y expresa nítidamente que el "pasado" está vivo y es constantemente resignificado.

\section{LISTA DE REFERENCIAS}

Argüello, L. (2010). Apertura política y violencia en México (1976-1988). Condiciones de visibilidad de agentes sociopolíticos no convencionales: el caso del Comité jEureka! (Tesis de maestría inédita), México, unAm.

Argüello, L. (2016). A la sombra de la contrainsurgencia. Violencia crónica y procesos de identificación política en Atoyac de Álvarez, Guerrero (Tesis de doctorado). México, El Colegio de México.

Aróstegui, J. (2004). La historia vivida. Sobre la historia del presente. Madrid: Alianza Editorial.

Barahona de Brito A., González Enríquez, C. y Aguilar, P. (2004). The politics of memory, transitional justice in democratizing societies. Nueva York: Oxford University Press.

Bellingeri, M. (2003). Del agrarismo armado a la guerra de los pobres. Ensayos de guerrilla rural en México. México: Juan Pablos Editor.

Catela da Silva, L. (2003). Apagón en el Ingenio, escrache en el museo. Tensiones y disputas entre memorias locales y memorias oficiales en torno a un episodio de represión de 1976. En E. Jelin y P. del Pino (comps.), Luchas locales, comunidades e identidades (pp. 63-106). Buenos Aires: Siglo XXI Editores.

Comverdad (Comisión de la Verdad para Guerrero). (15 de octubre de 2014). Informe final de actividades. Chilpancingo, Guerrero.

Crenzel, E. (2008). La historia política del Nunca más. La memoria de las desapariciones en Argentina. Buenos Aires: Siglo XXI Editores.

Dickson-Gómez, J. (2002). The sound of barking dogs: violence and terror among salvadoran families in the postwar. Medical Anthropology Quarterly, 16(4), 415-438.

Dutrénit S. y Argüello, L. (2011). Una gestión atrapada: el caso de la Femospr. En A. Cuéllar, F. Castañeda y E. Kuri (coords.), La crisis de las instituciones políticas en México, México: Facultad de Ciencias Políticas y Sociales-unAm.

Dutrénit, S. y Varela, G. (2010). Tramitando el pasado. Violaciones de los derechos humanos y agendas gubernamentales en casos latinoamericanos. México: Flacso-Clacso (Dilemas de la Política en Latinoamérica). 
Equipo Bourbaki (2011). El costo humano de la guerra por la construcción del monopolio del narcotráfico en México (2008-2009) (inédito), facilitado por el doctor Fernando Cortés.

Feldman, A. (1995). Epilogue. Ethnographic states of emergency. En C. Nordstrom y A. C. G. Robben, Fieldwork under fire. Contemporary studies of violence and survival (pp. 224-253). Londres: University of California Press.

Femospr (2006). Informe final de la Fiscalía Especial para la atención de delitos cometidos contra Movimientos Sociales y Políticos del Pasado (FEMOSPP). Recuperado de: http:// www.gwu.edu/ nsarchiv/NSAEBB/NSAEBB180/index2.htm

Foucault, M. (1980). La microfísica del poder. Madrid: Las Ediciones de la Piqueta.

Foucault, M. (1990). Genealogía del poder. Madrid: Las Ediciones de la Piqueta.

Goti, J. M. (2000). Terror y justicia en Argentina. Responsabilidad y democracia después de los juicios al terrorismo de Estado (pp. 167-239). Buenos Aires: De la Flor.

Gutiérrez, M. (1998). Violencia en Guerrero. México: La Jornada Ediciones.

Hayner, P. (2008). Verdades innombrables. El reto de las comisiones de la verdad. México: Fondo de Cultura Económica.

Honneth, A. (2009). Crítica del poder. Fases en la reflexión de una teoría crítica de la sociedad. Madrid: Mínimo Tránsito/Machado Editores.

Jelin, E. (2010). ¿Víctimas, ciudadanos o familiares? Las luchas por la legitimidad de la palabra. En E. Crenzel (coord.), Los desaparecidos en la Argentina. Memorias, representaciones e ideas (pp. 227-249). Buenos Aires: Biblos.

Jelin, E. (2002). Los trabajos de la memoria. Buenos Aires: Siglo XXI editores.

LeGoff, J. (1991). El orden de la memoria, el tiempo como imaginario. Barcelona: Paidós.

Merino, J., Zarkin, J. y Fierro, E. (1 de enero de 2015). Desaparecidos. Nexos. Recuperado de http://www.nexos.com.mx/?p=23811

Nino, C. (1997). El castigo como respuesta a las violaciones de derechos humanos. Una perspectiva global. En Juicio al mal absoluto. Los fundamentos y la historia del juicio a las juntas del proceso (pp. 17-75). Buenos Aires: EmecÉ.

Pécaut, D. (2000). Configurations of space, time, and subjectivity in a context of terror: The colombian example. International Journal of Politics, Culture, and Society. Colombia: A Nation and Its Crisis, 14(1), 129-150.

Radilla, A. y Rangel, C. (coord.) (2011). Desaparición forzada y terrorismo de Estado en México. Memorias de la represión de Atoyac, Guerrero durante la década de los sesenta. México: Universidad Autónoma de Guerrero/Plaza y Valdés.

Radilla, A. (1998). Poderes, saberes y sabores: una historia de resistencia de los cafeticultores, Atoyac, 1940-1974. Chilpancingo: Imprenta Candy. 
Román, J. (2007). Revuelta cívica en Guerrero, 1958-1962. México: Instituto Nacional de Estudios sobre la Revolución Mexicana.

Schwarzstein, D. (2001), Historia oral, memoria e historias traumáticas. Historia Oral, 4, 73-85.

Stern, S. J. (2000). De la memoria suelta a la memoria emblemática: hacia el recordar y el olvidar como proceso histórico (Chile, 1973-1998). En M. Garcés et al. (eds.), Memoria para un nuevo siglo: Chile, miradas a la segunda mitad del siglo Xx (pp. 11-33). Santiago: Ed. LOM.

Theydon, K. (2004), Entre prójimos. El conflicto armado interno y la política de reconciliación en el Perú. Lima: Instituto de Estudios Peruanos.

Todorov, T. (2000). Los abusos de la memoria. Barcelona: Paidós.

Vásquez, M. E. (2003). Viudez y estigma: efectos de la violencia política en familias de insurgentes. En P. Tovar R. (ed.), Familia género y antropología. Desafíos y transformaciones (pp. 249-270). Bogotá: ICAHN.

Wacquant, L. (2012). Castigar a los pobres. Barcelona: Gedisa.

\section{OTRAS FUENTES}

\section{Bibliografía}

Bartra, A. (2000). Guerrero bronco: campesinos, ciudadanos y guerrilleros en la Costa Grande. México: Ediciones Era.

Blacker, O. (2009). Cold war in the countryside: conflict in Guerrero, Mexico. The Americas Review, 66(2), 181-210.

Estrada, A. (2001). El movimiento anticaballerista: Guerrero 1960. Crónica de un conflicto. México: Universidad Autónoma de Guerrero.

Pollack, M. (2006). Memoria, olvido, silencio. La producción social de identidades frente a situaciones límite. La Plata: Ediciones Al Margen.

Rendón A., J. (2003). Sociedad y conflicto en el estado de Guerrero 1911-1995: poder político y estructura social de la entidad. México: Plaza y Valdez.

Schatz, S. (2011). Murder and politics in Mexico: political killings in Partido de la Revolucion Democratica and its Consequences. EUA: Springer-Verlag (Studies in Organized Crime 10). 


\section{Hemerografía}

Atl. Quincenario de Información y Análisis, Atoyac de Álvarez, Guerrero.

Despertar de la Costa, Zihuatanejo, Guerrero.

Diario Objetivo, Chilpancingo de Los Bravo, Guerrero.

La Jornada, México, D. F.

La Jornada Guerrero, Chilpancingo de Los Bravo, Guerrero.

El Sol de Acapulco. Acapulco de Juárez, Guerrero.

El Sur Acapulco. Diario de Guerrero. Acapulco de Juárez, Guerrero.

Trinchera. Política y Cultura, Chilpancingo de Los Bravo.

\section{Entrevistas}

Fuentes G., N. (12 de marzo de 2015). Entrevista a Nicomedes Fuentes García/Entrevistadora: Libertad Argüello. México, D. F.

Navarrete G., H. (8 de diciembre de 2014). Entrevista a Hilda Navarrete Gorjón/Entrevistadora: Libertad Argüello. Coyuca de Benítez, Guerrero. 